This is the author's manuscript for publication. The publisher-formatted version may be available through the publisher's web site or your institution's library.

\title{
Understanding the structure--emulsification relationship of gum ghatti - a review of recent advances
}

Ji Kang, Qingbin Guo, Glyn O. Phillips, and Steve W. Cui

\section{How to cite this manuscript}

If you make reference to this version of the manuscript, use the following information:

Kang, J., Guo, Q., Phillips, G. O., \& Cui, S. W. (2014). Understanding the structureemulsification relationship of gum ghatti $-\mathrm{A}$ review of recent advances. Retrieved from http://krex.ksu.edu

\section{Published Version Information}

Citation: Kang, J., Guo Q., Phillips, G. O., \& Cui, S. W. (2014). Understanding the structure-emulsification relationship of gum ghatti - A review of recent advances. Food Hydrocolloids, 42(Part 1), 187-195.

Copyright: () 2014 Elsevier Ltd.

Digital Object Identifier (DOI): doi:10.1016/j.foodhyd.2014.04.010

Publisher's Link:

http://www.sciencedirect.com/science/article/pii/S0268005X14001404

This item was retrieved from the K-State Research Exchange (K-REx), the institutional repository of Kansas State University. K-REx is available at http://krex.ksu.edu 


\title{
Understanding the Structure - Emulsification Relationship of Gum Ghatti - a
}

\section{review of recent advances*}

\author{
Ji Kang ${ }^{1}$, Qingbin Guo ${ }^{2}$, Glyn O. Phillips ${ }^{3,4}$ and Steve W. Cui ${ }^{2 * *}$ \\ * In honour of Professor Eric Dickinson - a great emulsification scientist
}

${ }^{1}$ Department of Grain Science and Industry, Kansas State University 201 Shellenberger Hall, Manhattan, KS 66506

${ }^{2}$ Guelph Food Research Centre, Agriculture and Agri-Food Canada, Guelph, Ontario, N1G 5C9, Canada

${ }^{3}$ Glyn O. Phillips Hydrocolloid Research Centre, Glyndwr University, Wrexham, Wales, LL11 2AW, UK

${ }^{4}$ Phillips Hydrocolloids Research Ltd, 45 Old Bond St., London W1S 4AQ

**Corresponding author: Tel.: +1 226217 8076; Fax: +1 2262178181 .

E-mail address: Steve.Cui @agr.gc.ca 


\begin{abstract}
This paper is based on a series of physical and chemical investigations to understand the structure-function properties of gum ghatti. After elucidating the detailed molecular structure of two gum ghatti fractions, the structure of its component glycoprotein was investigated whereby, the protein sequence and hydrophobicity were identified, followed by the conformational analysis of the gum and its fractions. Many techniques were used for the elucidation of the fine structures, which included methylation analysis-GC-MS, Maldi-TOF MS and 2D NMR spectroscopy, homonuclear ${ }^{1} \mathrm{H} /{ }^{1} \mathrm{H}$ correlations spectroscopy (COSY, TOCSY), heteronuclear ${ }^{13} \mathrm{C} /{ }^{1} \mathrm{H}$ multiplequantum coherence spectroscopy (HMQC) and heteronuclear multiple bond correlation (HMBC). Conformational properties were studied using a modelling system (Insight II) to relate the hydrophobicity of the protein moieties with the complex structures of the carbohydrates. These studies now provide an explanation for the excellent emulsification properties of gum ghatti in oil-in-water emulsions, which enable its application in the food, cosmetic and/or pharmaceutical industries.
\end{abstract}

Keywords: Gum Ghatti; Structure; Review; Emulsification; NMR 


\section{Introduction}

Gum Ghatti is an exuded gum from the Anogeissus latifolia tree, also known as the India Gum. Anogeissus is a genus of trees of the family Combretaceae, and have several species identified including A. acuminate (A. pendula), A. bentii, A. dhofarica, A. latifolia, A. leiocarpus (A. leiocarpa), A. rotundifolia, A. Schimperi and A. sericea. These trees are native to South Asia, the Arabian Peninsula, and Africa. The commercial significant gum ghatti became available due to the establishment of plantations in India and the development of new processing methods include cleaning, grading and spray drying (Al-Assaf, Phillips, and Amar, 2009). The newly developed gum ghatti has been named GATIFOLIA which is a spray-dried powder processed from specially selected high quality gum ghatti. It is highly soluble with consistent colour (Al-Assaf, Phillips, \& Amar, 2009). In the USA, gum ghatti is approved as GRAS (generally regarded as safe), and is widely used in pharmaceuticals, the paper industry, wax emulsions and other industries.

An important feature of gum ghatti is its excellent emulsification properties. The emulsification ability of gum ghatti is superior even to that of gum Arabic or any other natural gums. It is effective at concentrations as low as $35 \%$ of those of gum Arabic to produce stable emulsions. It is also effective in formulations which are difficult to stabilize with gum Arabic or other available commercial gums (Al-Assaf, Amar, \& phillips, 2008; Castellani, Al-Assaf, Axelos, Phillips, \& Anton, 2010; Castellani, Gaillard, et al., 2010; Jefferies, Konadu, \& Pass, 1982; Jefferies, Pass, \& Phillips, 1977; Jefferies, Pass, Phillips, \& Zakaria, 1978; Kaur, Singh, \& Singh, 2009). More active gum component is adsorbed on to the oil droplets in the emulsions $(30 \% \mathrm{w} / \mathrm{w})$ than that of gum Arabic (7\%-10\%) (Katayama et al., 2008). Moreover, the adsorbed components of 
gum ghatti in the emulsions are distributed evenly throughout the whole molecular weight range, whereas only the high molecular weight fraction of gum Arabic is adsorbed on to the oil surface (Katayama, et al., 2008). This means that all gum ghatti fractions are surface active, but only the high molecular weight arabinogalactan protein fraction supports emulsification for gum arabic. Furthermore, the protein content of gum ghatti is higher than that of gum Arabic (Al-Assaf, et al., 2008).

To understand this effective structure-function relationship gum ghatti was fractionated and the structure of each of the four fraction, including the protein moieties, were characterized in relation to their conformational properties (Kang, Cui, Chen, et al., 2011; Kang, et al., 2012; Kang, Cui, et al., 2011a, 2011b; Kang, Guo, Wang, Phillips, \& Cui; Kang, Guo, Wang, Phillips, \& Cui). This review will summarize these advances in elucidating the fine structures of gum ghatti and explain why it is probably the best natural emulsifier.

\section{Fractionation and physicochemical characterization of the gum Ghatti}

Gum ghatti is mainly composed of $89.67 \%$ polysaccharide and $8.04 \%$ of moisture, $4.34 \%$ of protein and $2.25 \%$ of ash. Arabinose and galactose make up about $90 \%$ of the total sugar content. Rhamnose, arabinose, galactose, xylose, mannose and glucose are present in the molar ratio of 1.7: 38.7: 22.9: 1.8: 1.9: 0.7 . The polysaccharide of gum ghatti is heterogeneous, in order to get structurally more homogenous components, gum ghatti was fractionated into four fractions using the gradual ethanol precipitation. Ethanol (100\%) was added slowly into gum ghatti solution $(15 \% \mathrm{w} / \mathrm{v})$ to achieve ethanol concentrations of $50 \%, 65 \%$ and $80 \%(\mathrm{v} / \mathrm{v})$ in a stepwise manner. The corresponding 
precipitate at each step was obtained and designated F50, F65 and F80, respectively. The final supernatant was recovered as FS. The yield of each fraction is 4.45\% (F50), 47.59\% (F65), 36.10\% (F80) and 2.77\% (FS). (Kang, Cui, Chen, et al., 2011).

Although no big differences were observed in weight average molecular weight $\left(\mathrm{M}_{\mathrm{w}}\right)$ between F50, F65. F80, and the original gum and the first peak of FS (FS also has a second peak of small $\mathrm{Mw}$ ), the physicochemical and functional properties of these four fractions varied considerably in terms of chemical and monosaccharide composition, rheological properties and surface activities. The uronic acid content decreased in the order of F50 (14.31\%), F65 (12.42\%), F80 (9.26\%) and FS (2.03\%). The protein content also varied considerably among the fractions: FS contained $4.63 \%$ protein, while in F50, F65 and F80, the protein content were $3.78 \%, 2.35 \%$ and $1.99 \%$ respectively. The monosaccharide analysis showed the amount of galactose decreased significantly along the series of F50, F65, F80 and FS $(37.27 \%, 29.09 \%, 26.57 \%$ and $16.43 \%)$ whereas the amount of arabinose increased substantially along this series $(49.69 \%, 63.44 \%, 69.21 \%$ and $72.85 \%$, respectively). F50 had a higher rhamnose content (8.03\%) compared to the other fractions. Gum ghatti and its fractions exhibited Newtonian flow behavior until gum concentrations reached to $20 \%(\mathrm{w} / \mathrm{v})$, above which it showed some shear-thinning behavior. At the same shear rate and concentration, the apparent viscosities of these fractions decreased in the order of: F50 $>$ F65 $>$ F80 $>$ FS. Surface activity measurements indicated that all of those four fractions showed an ability to decrease the water surface tension $(72.8$ dynes $/ \mathrm{cm})$ in the order $\mathrm{FS}>>\mathrm{F} 50>\mathrm{F} 65>\mathrm{F} 80$ within the concentrations $0.01 \%-1.50 \%$ and is probably related to the protein content $(\mathrm{F} 50<\mathrm{F} 65<\mathrm{F} 80)$ and structural properties. 
Preliminary structural analysis (FTIR, methylation analysis and 1D NMR) showed a structural similarity between F50, F65 and F80 but a different degree of branching. The total amount of terminal sugar units were $34.96 \%, 38.27 \%, 40.77 \%$ in F50, F65 and F80, respectively based on the methylation analysis results. However, the molecular structure of FS is significantly different from the other fractions. For example, 1H NMR spectrum showed several new peaks for FS within the region of 4.8-5.0 ppm and 4.60-4.68 ppm when compared with the other fractions. Some signals at 96.6, 92.5, 87, 81.8, 66.2, 63 and $62.5 \mathrm{ppm}$ in ${ }^{13} \mathrm{C}$ spectrum of FS, were not found in the other fractions (Fig.1). Therefore, we selected F80 and FS as representatives of gum ghatti for further investigation of their detailed structures.

\section{Structural identification of an arabinogalactan (F80) from gum ghatti}

Previously, the available information about the structure of gum ghatti was mainly derived from the classical studies of Aspinall and co-workers from 1955 to 1965 (Aspinall, Auret, \& Hirst, 1958a, 1958b; Aspinall, Bhavanan, \& Christen, 1965; Aspinall \& Christen, 1965; Aspinall, Hirst, \& Wickstrom, 1955). Due to the limitation of the analytical tools available then, the structure information is not complete.

The structure feature of the major fraction (F80) (Gatifolia SD) was investigated systematically using combined methods of methylation analysis and 1D \& 2D NMR spectroscopy. The majority of the terminal units in F80 were identified as t-L-Araf (36.28\%), with small amount of t-GlcpA (1.89\%), t-oArap (1.73\%), and trace amounts of t-Rhap and t-Galp. The most branched sugar residue was $\rightarrow 3,4,6-\mathrm{Gal} p(1 \rightarrow$, which accounts for $14.20 \%$ of total sugar residues. And the second largest branching unit was 1,3,6-O linked Galp (5.10\%), which was newly identified in gum ghatti by our group. 
Also, the relative amount of $\rightarrow 2,3,6-\operatorname{Gal} p(1 \rightarrow, \rightarrow 2,3,5-\operatorname{Araf}(1 \rightarrow$ and $\rightarrow 2,3-\operatorname{Man} p(1 \rightarrow$ was $4.87 \%, 4.09 \%$, and $2.34 \%$, respectively. The unsubstituted sugar residues included: $\rightarrow 4$-GlcpA $(1 \rightarrow, \rightarrow 6$-D-Gal $p(1 \rightarrow, \rightarrow 2$-L-Araf $(1 \rightarrow, \rightarrow 3$-L-Araf $(1 \rightarrow, \rightarrow 5$-L-Araf $(1 \rightarrow$ and $\rightarrow 3-\mathrm{D}-\mathrm{Gal} p(1 \rightarrow$, in the molar ratio of 6.90: 5.59: 4.42: 3.46: 3.18: 1.08 .

The ${ }^{1} \mathrm{H}$ NMR spectrum (Fig 2a) showed more than ten peaks in the anomeric region (4.3-5.8 ppm), which confirmed the complexity of the structure. Combining the data from 1H, 13C, COSY, TOCSY and HMQC spectra and by the comparison with previous reports, the complete ${ }^{1} \mathrm{H}$ and ${ }^{13} \mathrm{C}$ assignments of sugar residues: T- $\alpha$-L-Araf $(1 \rightarrow, \mathrm{T}-\alpha-\mathrm{L}-$ Rhap $(1 \rightarrow, \rightarrow 4)-\beta-\mathrm{D}-\mathrm{GlcpA}(1 \rightarrow, \rightarrow 6)-\beta-\mathrm{D}-\mathrm{Gal} p(1 \rightarrow, \rightarrow 3)-\alpha-\mathrm{L} \quad$-Araf $\quad(1 \rightarrow \quad$ were successfully achieved. The other sugar residues $\rightarrow 2)$ - $\alpha$-L-Araf $(1 \rightarrow, \rightarrow 3,4,6)-\beta-D-$ $\operatorname{Gal} p(1 \rightarrow$, and $\rightarrow 2,3,5)-\alpha-\operatorname{L}-\operatorname{Araf}(1 \rightarrow$ were identified by comparing with the data from NMR spectra of the FS fraction. (Kang, Cui, et al., 2011a)

The connecting sequences of the assigned sugar residues established from HMBC spectroscopy (Fig. 2b) were terminal arabifuranosyl residues linked to $\rightarrow 3-\alpha$-L-Araf-1 $\rightarrow$ through 1,3-O- glycosidic bonds; terminal arabifuranosyl residues linked to $\rightarrow 6-\beta-\mathrm{D}-$ Gal $p-1 \rightarrow$ through 1,6 -O- glycosidic bonds; T- $\alpha$-L-Rhap linked to $\rightarrow 3-\alpha$-L-Araf-1 $\rightarrow$ through 1,3-O- glycosidic bonds. Therefore, the structure of F80 could then be defined. The backbone is composed of 1,6-linked galactopyransyl (Galp) residues substituted at $O-3$ and $O-4$ position, which can be classified as the "hairy region", while the "smooth region" consists of $\rightarrow 2)$-Araf-( $1 \rightarrow 4)$-GlcpA- $(1 \rightarrow 6)-$ Gal $p-(1 \rightarrow 6)-G a l p-(1 \rightarrow$. Side chains are terminated by arabinofuranosyl (Araf) and occasionally by rhamnopyranosyl (Rhap), arabinopyranosyl (Arap), Gal $p$ and glucuronopyranosyl (GlcpA) residues, as shown in Fig. 3 
The proposed structure provides a complete structure for F80, and is in partial agreement with the previous proposals: sugar residue $\rightarrow 6-\mathrm{Gal} p(1 \rightarrow$ substituted at $O-3$ and $O-4$ as identified in previously (Aspinall, et al., 1958a, 1958b; Aspinall, Bhavanan, et al., 1965; Aspinall \& Christen, 1965; Aspinall, et al., 1955). The linkage $\rightarrow 4$ )-GlcpA$(1 \rightarrow 6)-G a l p-(1 \rightarrow 6)-G a l p-(1 \rightarrow$ was previously proposed in a free reducing oligosaccharide from gum ghatti (Tischer, Iacomini, Wagner, \& Gorin, 2002).

\section{Structure the globular polysaccharide fraction gum ghatti (FS)}

The structure of the fraction FS was investigated also to understand its high surface activity. (Kang, Cui, et al., 2011b). Both methylation analysis and 1D \& 2D NMR spectroscopy were used. The methylation analysis indicated T-Araf is the most important terminal unit, which accounts for $25.32 \%$ of the residues. Other neutral non-reducing terminal units are t-Arap, t-Galp and t-Rha with the molar ratio of 3.49\%, $2.30 \%$ and $0.97 \%$, respectively. Most of $\rightarrow 1)$-Gal $p-(6 \rightarrow$ residues are substituted at 3,4 positions $(17.73 \%)$ and 3 position $(4.96 \%)$. Another important branch point is $\rightarrow 1)$-Araf- $(5 \rightarrow$ substituted at $2-\mathrm{O}$ and $3-\mathrm{O}$ positions, which accounts for $8.57 \%$ of the total residues. Glucuronic acid was shown to be as t-GlcpA $(2.77 \%)$ and $\rightarrow 1)-G l c p A-(4 \rightarrow(1.10 \%)$ in the FS fraction. The unsubstituted residues were shown to be $\rightarrow 1)$-Araf-(2 $\rightarrow, \rightarrow 1)$-Araf-

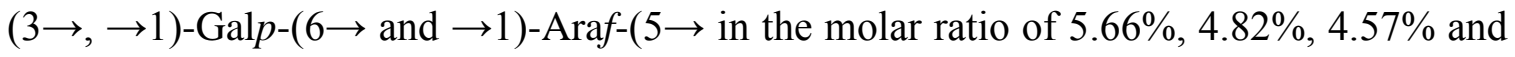
$4.02 \%$, respectively.

The ${ }^{1} \mathrm{H}$ NMR spectrum of FS (Fig. 4a) shows more than sixteen peaks in the anomeric region, which is more complex than F80. ${ }^{1} \mathrm{H},{ }^{13} \mathrm{C}, \mathrm{COSY}$, TOCSY and HMQC spectra showed the presence of $\rightarrow 2,3,5)$ - $\alpha$-L-Araf $(1 \rightarrow, \rightarrow 3,4,6)-\beta-\mathrm{D}-\mathrm{Gal} p(1 \rightarrow, \rightarrow 5)$ - $\alpha$ - 
L-Araf(1 $(\rightarrow, \rightarrow 2)-\alpha-L-\operatorname{Ara} f(1 \rightarrow, \rightarrow 4)-\beta-D-G l c p A-(1 \rightarrow, \rightarrow 6)-\beta-D-G a l p-(1 \rightarrow, \alpha-L-R h a p-$ $(1 \rightarrow, \rightarrow 5)$ - $\alpha$-L-Araf-( $1 \rightarrow, \rightarrow 2,3,5)-\alpha$-L-Araf- $(1 \rightarrow$. Complete assignments of these sugar residues were also established.

Some connecting sequences of these sugar residues were identified based on HMBC (Fig. 4b) spectroscopy. These were: t-Rha linked to 2,3,5-Araf and 3-Araf, respectively; $\rightarrow 4)-\beta-D-G l c p A-(1 \rightarrow$ linked with the residue $\rightarrow 6)-\beta-D-G a l p-(1 \rightarrow$ by a $1,6-O$ glycosidic bond; some of the terminal arabifuranosyl residues were linked to 3- $\alpha$-Araf through 1,3O- glycosidic bonds; some of terminal arabifuranose was linked to 6- $\beta$-Gal $p$ through 1,6O- glycosidic bonds; terminal arabifuranosyl residues were linked to the 2 -O of $\rightarrow 2,3,5$ )$\alpha-\mathrm{L}-\mathrm{Araf}-(1 \rightarrow, 3-\mathrm{O}$ of $\rightarrow 3,4,6)-\beta-\mathrm{D}-\mathrm{Gal} p-(1 \rightarrow, 2-\mathrm{O}$ of $\rightarrow 2)-\alpha-\mathrm{L}-\mathrm{Araf}-(1 \rightarrow$ and $5-\mathrm{O}$ of $\rightarrow 5)$ - $\alpha$-L-Araf- $(1 \rightarrow$; $\rightarrow 2)-\alpha$-L-Araf- $(1 \rightarrow$ was linked to O-4 of $\rightarrow 4)-\beta$-D-GlcpA-( $1 \rightarrow$. In addition, two $\rightarrow 3,4,6)-\beta-\mathrm{D}-\mathrm{Gal} p-(1 \rightarrow$ were linked to each other through an $1,6-\mathrm{O}$ glycosidic bond; two $\rightarrow 2,3,5)$ - $\alpha$-L-Araf- $(1 \rightarrow$ were linked with each other through a 1,5 O glycosidic bond.

On this basis a structure could be proposed: 1,6-linked galactopyransyl (Galp) is the backbone, branched at O-3 and O-4 positions by various of sugar residues, including $\rightarrow 6)-\beta-D-G a l p-(1 \rightarrow, \rightarrow 2)-\alpha-L-A r a f-(1 \rightarrow, \rightarrow 5)-\alpha-L-A r a f-(1 \rightarrow$, t- $\alpha-L-A r a f$ and $\rightarrow 2,3,5)-$ $\alpha$-L-Araf-( $1 \rightarrow$. Moreover, the $\rightarrow 2,3,5)-\alpha$-L-Araf-( $1 \rightarrow$ residue can have two side chains at O-2 and O-3 position. Most of the side chains have terminal arabinofuranosyl (Araf), and are occasionally terminated by rhamnopyranosyl (Rhap), arabinopyranosyl (Arap), Galp and glucuronopyranosyl (GlcpA) residues. Some of the side chains extend to five sugar units (Fig. 5).

In comparison to F80, fraction FS is much more branched and has longer side chains. 
These structural features are consistent with the physical properties such as the FS fraction (FS being more soluble than F80). This multi-branched structure most likely accounts for the special physical properties, including the excellent surface activities exhibited by FS.

\section{Identifying the covalent bonds between protein and polysaccharide moieties}

Two different explanations have been proposed to account for the mechanism of hydrocolloid emulsifiers. One identifies the small amount of protein covalently linked to the carbohydrate molecule to be the hydrophobic group adsorbed to the oil droplet (Dickinson, 1989, 2011; Dickinson \& Nicolai, 2009). Others consider that a hydrophobic group on the carbohydrate hydrocolloid likes $\mathrm{CH}_{3}$ from rhamnose, or some other intermolecular effect can cause the binding between emulsifier and oil droplet (Garti \& Leser, 2001; Garti, Madar, Aserin, \& Sternheim, 1997). However, for gum Arabic, it has been proved that it is the arabinogalactan protein component (AGP), which contributes most of the emulsifying ability (Randall, Phillips, \& Williams, 1988), since it contains a peptide backbone, which can bind to the oil droplets.

Gum ghatti as an excellent emulsifier, so which part of the molecule contributes to the oil binding effect? About $4 \%$ of protein is present in gum ghatti. Does it linked with carbohydrate part? This is the question we have sought to answer.

Gum ghatti were partial hydrolyzed by $0.1 \mathrm{M}$ TFA $(10 \mathrm{~mL})$ at $100{ }^{\circ} \mathrm{C}$ for $20 \mathrm{~min}$, 60min, 120min, and 3.5h, as shown in Fig. 6. Partial acid hydrolysis can sequentially cut the molecules. Branches were cleaved first and then backbone. The removed branches were collected in supernatants after ethanol 'precipitation (20S, 60S, $120 \mathrm{~S}$ and 3.5S); the 
remaining large molecule parts were in the precipitated fractions $(20 \mathrm{P}, 60 \mathrm{P}, 120 \mathrm{P}$ and 3.5P). The hydrolyzed products were monitored by HPSEC coupled with RI and UV detectors and the results are shown in Figure 7. With increasing of hydrolysis time, more branches were cut off from the molecule, and the $\mathrm{M}_{\mathrm{w}}$ of remained large molecule decreased gradually. Most significantly, with the decrease of $M_{w}$ of the first peak of each hydrolysate, the retention volumes of the peaks were always the same in UV and RI profile, as shown in Fig. 7. These were 15.614, 17.042, 17.172, 18.006 and $18.176 \mathrm{ml}$ for the original gum ghatti, 20P, 60P, 120P and 3.5P, respectively. This information indicates that the protein and polysaccharide are linked covalently. On the other hand, the protein content in the supernatant fractions of partial acid hydrolyzed products, 20S, 60S, 120S and $3.5 \mathrm{~S}$ were $3.26 \%, 1.40 \%, 1.76 \%$, and $1.16 \%$, whereas the protein content in the precipitate $(20 \mathrm{P}, 60 \mathrm{P}, 120 \mathrm{P}$ and $3.5 \mathrm{P})$ were all higher than $10 \%$. These results further confirmed that the proteins were accumulated in the precipitate fraction and covalently linked with the polysaccharide (Kang, et al., 2012).

The amino acid composition and protease hydrolysis results indicated that the linkage between polysaccharide and protein were different from that of gum Arabic, which are proposed to have a wattle blossom type structure (Fincher, Stone, \& Clarke, 1983).

The structure of gum ghatti glycoprotein was investigated by Maldi-TOF MS and 1D\&2D NMR spectroscopy (Kang, et al., 2012). Combined with the polysaccharide data, a structure model was proposed. A 1,6-linked galactose backbone has numerous side chains. Occasionally, xylose and mannose also appear on the backbone. Proteins or polypeptides are attached directly to the core of the polysaccharide. The linkage site of 
amino acids and polysaccharides was determined to be N-linked (Hex $)_{n}-$ GlcNAc-Asn, as shown in Fig. 8.

\section{Structure of the protein moiety and the hydrophobicity of Gum Ghatti}

The proteinacous part of gum ghatti plays an important role in the emulsifying properties of gum ghatti. Recently, we have examined the physicochemical properties and amino acid sequences of the protein moiety of gum ghatti (Kang, et al.). First, gum ghatti was hydrolyzed with dilute TFA acid for $3.5 \mathrm{~h}$ to give $3.5 \mathrm{P}$, which contains $14 \%(\mathrm{w} / \mathrm{w})$ of protein (Kang, et al., 2012). This process does not destroy the linkage between the protein and the polysaccharide. Then the carbohydrate part of $3.5 \mathrm{P}$ was removed by trifluoromethanesulfonic acid (TFMS). The remaining components were purified by sodium dodecyl sulphate-polyacrylamide gel electrophoresis (SDS-PAGE). The sample slices were excised from the gel, and trypsin in-gel digestion was carried out to cleave protein into smaller molecular weight peptides. These peptides were first separated by HPLC, ionized, and then mass and MS/MS spectra were obtained. Each peptide sequence was identified by the specific ions in the MS/MS spectrum. Nine peptides were obtained and listed in Table 2 (Kang, et al.). The hydrophobic score of each fragment was calculated. Among all the peptides analyzed, PVLEHELVPAR peptide exhibited the highest hydrophobic score of 566, which was much higher than that of gum arabic peptides (241), as calculated by Goodrum (Goodrum, Patel, Leykam, \& Kieliszewski, 2000)

The hydrophobicity of the amino acids in peptides influences their surface activities, and emulsifying capacity. The more hydrophobic groups are present the stronger the 
binding between the emulsifier and oil droplet (Kato \& Nakai, 1980). Dr. Steve Cui's group (Kang, et al.) characterized the hydrophobicity of the protein in gum ghatti by its Hydrophobic score, which was calculated from the hydrophobic index of each type of amino acid and its percentage present Gum ghatti (24.05) has higher hydrophobic score than that of gum arabic (18.62) (Al-Assaf, Phillips, \& Amar, 2009), which could account for the superior emulsifying properties of gum ghatti. Furthermore, there are more hydrophobic groups in gum ghatti than in gum arabic. Kang et al's (Kang, et al.) study also indicated that the amount of positively and negatively charged groups of gum ghatti is similar. So the protein is in a more expanded conformation than in gum arabic. When the protein is expanded, the hydrophobic groups are in better contact with the oil and water interphase, and so bind to the oil more readily. The opposite occurs when the protein structure is folded and so become less accessible. The expanded molecule can also adjust its conformation at the oil-water interface, such that the hydrophobic groups bind easier to the oil (Cabra, Arreguín, \& Farres, 2008).

The amino acid sequences in gum ghatti were investigated and compared with those of gum Arabic and the hydrophobic score calculated (Kang, et al.). Gum ghatti has long hydrophobic amino acid sections, such as, Ala-Thr-Cys-Leu (ATCL), Tyr-Thr-Ala (YTA) and Ala-Leu-Thr (ALT). These are similar to the sequences in $\beta$-Casein, which has sections with least six hydrophobic amino acids. The clusters of high hydrophobic amino acids of gum ghatti are grouped in a more consecutive manner than in gum Arabic, with almost every peptide fragment containing hydrophobic groups. This broadly distributed hydrophobic amino acid clusters along the whole protein molecule make it accessible for the absorption to the non-polar oil phase. 


\section{Conformation properties of gum ghatti}

The conformation of gum ghatti has a direct link to its physical-chemical properties. Conformation and solution properties of gum ghatti and fractions (F50, F65, F80 and FS) were investigated by multi-angle static, dynamic light scattering and HPSEC-multiple detectors (Kang, et al.). Gum ghatti exhibited random coil conformation with average hydrodynamic radius of $23 \mathrm{~nm}$ and $35.1 \mathrm{~nm}$ of average radius gyration. It also showed some trends of conformation among its fractions. Three fractions are random coil; F50 has a loosely extended chain conformation, the chains are much rigid than other that of other fractions, while F80 is more compact and close to the spherical conformation. F65 are in between of F50 and F80. The $\mathrm{M}_{\mathrm{w}}$ of F50, F65 and F80 are 590.0, 863.3 and 1211.2 $\mathrm{kD}$, with the molecular size, given by $\mathrm{R}_{\mathrm{g}}$ and $\mathrm{R}_{\mathrm{h}}$, increasing in the order: F50, F65 and F80, which is consistent with molecular weights.

All the fractions of gum ghatti molecules formed aggregates in pure water and $0.2 \mathrm{M}$ $\mathrm{NaCl}$ solutions, with the apparent mean diameter of 360.52 and $217.43 \mathrm{~nm}$, respectively. The aggregates can be successfully eliminated by dissolving in $0.5 \mathrm{M} \mathrm{NaOH}$ solution and the solution was stable for two days at room temperature (Kang, et al.). The second viral coefficient $\left(\mathrm{A}_{2}\right)$, as a quantitative indicator of the affinity between polymer and solvent showed the same results (Table 1). The intrinsic viscosity for F50, F65 and F80 were $0.473,0.751$ and $0.595 \mathrm{dl} / \mathrm{g}$, respectively. The number average molecular weight $(\mathrm{Mn})$, Mark-houwink equation parameters $(\alpha)$ and $\log \kappa$ are listed in Table 1 . The 3D molecular model of F80 and FS were simulated according to the detailed molecular structure (Fig. 9) by a computer modeling technique, which visualized a chain conformation of random coil close to sphere of F80, and sphere shape for FS. 
The methylation results (Kang, Cui, Chen, et al., 2011) gave the terminal units content of F50, F65 and F80 to be 39.28\%, 43.63\% and 49.69\% respectively. The degree of branching increased in the order of $\mathrm{F} 50<\mathrm{F} 65<\mathrm{F} 80$. The conformation of F50 is a random coil. F65 and F80 are random coils but close to sphere conformation (Kang, et al.). It is worth noting that the apparent viscosity of these fractions decreases in the order of F50>F65>F80 (Kang, Cui, Chen, et al., 2011), while the $\mathrm{M}_{\mathrm{w}}$ and size of these fractions increased in this order. The friction arising when molecules interact with each other causes the viscosity of polymers. At equal concentrations, the larger the hydrodynamic volume occupied by polysaccharide molecules in solution, the greater is the viscosity they generate. The volume swept out by the dynamic motions of polysaccharide molecule in solution is influenced by both its size and shape (BeMiller, 2007). The size of gum ghatti fractions increase in the order of $\mathrm{F} 50<\mathrm{F} 65<\mathrm{F} 80$, whereas the shapes are different, and the chain conformation ranging from loose to compact (Kang, et al.). For the same size molecules, the more compact of the structure, the smaller is the hydrodynamic volume. Thus the smallest size F50 had the highest apparent viscosity among all the fractions. In summary, the degree of branching influences the conformation, and together the structure and conformation features determine the physical properties of the gum ghatti fractions.

The highly branched molecular structure of gum ghatti, to some extend, led to the random coil close to sphere conformation of molecules. The structural characteristics and the relative compact conformation, as well as the conjugation between polysaccharide and protein contributed to the excellent emulsification and stabilization properties. 
The conformations of gum ghatti protein fragments were simulated using computer modeling techniques (Kang, et al.). Met-Leu-Pro-Val-Leu-Glu-His-Glu-Leu-Val-ProAla-Arg, which has relatively high hydrophobicity (566); the conformation image revealed that the surface of the molecule was mainly covered by aliphatic groups, which can bind oil droplets on oil in water emulsion. The snapshot of protein fragment with the lowest hydrophobic score (125), the amino acid sequence was Cys-Lys-Lys-Glu-Val-Glu, hydrophilic groups, such as, $\mathrm{NH}_{2}, \mathrm{OH}$ groups were located at the out layer of the molecule.

By combining the highly branched structures (Kang, et al., 2012; Kang, Cui, et al., 2011a, 2011b) with a random coil conformation (Kang, et al.) for the polysaccharide moiety, it is possible to envisage the interactions at the oil and water interphase (Fig. 10). The polysaccharide component acts as steric layer to keep oil droplets away from each other, preventing coalescence. The protein moiety with hydrophilic groups directed toward outside of the molecule can bind the oil droplet at oil and water interphase. There are numerous protein hydrophobic groups located towards outside of molecules which could be the anchor points for the oil droplets, as shown in Fig. 10, where the red curved lines represent proteins; the fragments directed toward the oil droplet are the hydrophobic groups of the protein, such as leu-val-val, ala-thr-cys-leu, tyr-thr-val of gum ghatti protein moity. Different carbohydrate blocks, i.e. F50, F65, F80 and FS, areclinked with the proteins.

To stabilize an emulsion, the hydrophobic domain of the protein needs to be oriented toward the oil phase. The random coil conformation of the carbohydrate moiety of gum ghatti molecules allows it to adjust its conformation and expose the hydrophobic 
groups. These can then attach to the non-polar phase more readily. Compared to gum arabic, the protein moiety of gum ghatti has higher hydrophobic score and has longer hydrophobic amino acids sections. Thus, the specific structure of protein moiety combined with its highly branched polysaccharide moiety makes up its unique structure, which accounts for superior emulsifying properties.

\section{Summary}

The structures which make up gum ghatti have been described. For the first time covalent bonds between protein and polysaccharide of gum ghatti have been located. The carbohydrate structure and its direct linkage to protein enable a better understanding of its functional properties. The 3D molecular models of gum ghatti illustrate its highly branched polysaccharide structure and high hydrophobicity of the proteins based on the

proposed amino acid sequence. The random coil chain conformation was visualized using computer modeling and related to the light scattering data.

The main features of the structure-function relationship are:

- the highly branched molecular structure of gum ghatti leads to the random coil and globular conformation of the molecules

- the covalently linked highly hydrophobic protein moieties are the key factor for gum ghatti to be absorbed on the surface of the oil droplets molecules

- the combination of the random coil/globular conformation of the highly branched polysaccharides and the affinity of the linked protein moieties for the oil phase explain why gum ghatti is such an excellent emulsifier in oil-in-water emulsions. 


\section{References}

Al-Assaf, S., Phillips, G. O., \& Amar, V. (2009). 'Gum ghatti'. In G. O. Phillips \& P. A. Williams (Eds.), Handbook of hydrocolloids (2nd ed., pp. 477-497): Woodhead Publishing.

Aspinall, G. O., Auret, B. J., \& Hirst, E. L. (1958a). Gum ghatti (Indian gum). Part II. The hydrolysis products obtained from the methylated degraded gum and the methylated gum. Journal of the Chemical Society(JAN), 221-230.

Aspinall, G. O., Auret, B. J., \& Hirst, E. L. (1958b). Gum ghatti (Indian gum). Part III. Neutral oligosaccharides formed on partial acid hydrolysis of the gum. Journal of the Chemical Society(DEC), 4408-4418.

Aspinall, G. O., Bhavanan, V. P., \& Christen, T. B. (1965). Gum ghatti (Indian gum). Part V. Degradation of the periodate-oxidised gum. Journal of the Chemical Society(APR), 2673-2676.

Aspinall, G. O., \& Christen, T. B. (1965). Gum ghatti (Indian gum). Part IV. Acidic oligosaccharides from the gum. Journal of the Chemical Society(APR), 26772684.

Aspinall, G. O., Hirst, E. L., \& Wickstrom, A. (1955). Combreturn leonense Gum. Part I. Partial Hydrolysis of the Gum. Journal of the Chemical Society, 1160-1165.

BeMiller, J. N. (2007). carbohydrate chemistry for food scientists ( $2^{\text {nd }}$ ed.). St. Paul: AACC international, Inc.

Cabra, V., Arreguín, R., \& Farres, Y. A. (2008). Emulsifying properties of proteins. Boletín de la Sociedad Química de México, 2(2), 10.

Dickinson, E. (1989). Food colloids -- An overview. Colloids and Surfaces, 42(1), 191204.

Dickinson, E. (2011). Food colloids research: Historical perspective and outlook. Advances in Colloid and Interface Science, 165(1), 7-13.

Dickinson, E., \& Nicolai, T. (2009). Food Colloids, Le Mans, April 2008. Food Hydrocolloids, 23(4), 1073-1073.

Fincher, G. B., Stone, B. A., \& Clarke, A. E. (1983). Arabinogalactan-Proteins-structure, Biosyntesis, and Function. Annual Review of Plant Physiology and Plant Molecular Biology, 34, 47-70.

Garti, N., \& Leser, M. (2001). Emulsification properties of hydrocolloids. Polymers for Advanced Technologies, 12(1-2), 123-135. 
Garti, N., Madar, Z., Aserin, A., \& Sternheim, B. (1997). Fenugreek Galactomannans as Food Emulsifiers. Lebensmittel-Wissenschaft und-Technologie, 30(3), 305-311.

Goodrum, L. J., Patel, A., Leykam, J. F., \& Kieliszewski, M. J. (2000). Gum arabic glycoprotein contains glycomodules of both extensin and arabinogalactanglycoproteins. Phytochemistry, 54(1), 99-106.

Kang, J., Cui, S. W., Chen, J., Phillips, G. O., Wu, Y., \& Wang, Q. (2011). New studies on gum ghatti (Anogeissus latifolia) part I. Fractionation, chemical and physical characterization of the gum. Food Hydrocolloids, 25(8), 1984-1990.

Kang, J., Cui, S. W., Guo, Q., Chen, J., Wang, Q., Phillips, G. O., \& Nikiforuk, J. (2012). Structural investigation of a glycoprotein from gum ghatti. Carbohydrate Polymers, 89(3), 749-758.

Kang, J., Cui, S. W., Phillips, G. O., Chen, J., Guo, Q., \& Wang, Q. (2011a). New studies on gum ghatti (Anogeissus latifolia) part II. Structure characterization of an arabinogalactan from the gum by 1D, 2D NMR spectroscopy and methylation analysis. Food Hydrocolloids, 25(8), 1991-1998.

Kang, J., Cui, S. W., Phillips, G. O., Chen, J., Guo, Q., \& Wang, Q. (2011b). New studies on gum ghatti (Anogeissus latifolia) Part III: Structure characterization of a globular polysaccharide fraction by 1D, 2D NMR spectroscopy and methylation analysis. Food Hydrocolloids, 25(8), 1999-2007.

Kang, J., Guo, Q., Wang, Q., Phillips, G. O., \& Cui, S. W. New studies on gum ghatti (Anogeissus latifolia) Part 5: The Conformational Properties of Gum Ghatti. Food Hydrocolloids, submitted.

Kang, J., Guo, Q., Wang, Q., Phillips, G. O., \& Cui, S. W. New studies on gum ghatti (Anogeissus latifolia) Part 6: Physicochemical Characteristics of the Protein Moiety of Gum Ghatti. Food Hydrocolloids, Submitted.

Randall, R. C., Phillips, G. O., \& Williams, P. A. (1988). The role of the proteinaceous component on the emulsifying properties of gum arabic. Food Hydrocolloids, 2(2), 131-140.

Tischer, C. A., Iacomini, M., Wagner, R., \& Gorin, P. A. (2002). New structural features of the polysaccharide from gum ghatti (Anogeissus latifola). Carbohydr Res, 337(21-23), 2205-2210. 


\section{Figure Captions}

Fig. $1{ }^{1} \mathrm{H}$ NMR anomeric region of four fractions from Gatifolia SD

Fig. $2{ }^{1} \mathrm{H}$ NMR (a) and HMBC (b) spectrum of F80 isolated from gum ghatti.

Fig. 3 Proposed structure of F80

Fig. $4{ }^{1} \mathrm{H}$ NMR (a) and HMBC (b) of FS isolated from gum ghatti

Fig. 5 Proposed structure of FS

Fig. 6 Procedure for partial acid hydrolysis of Gatifolia SD

Fig. 7 HPSEC profiles from RI and UV signals of mild acid hydrolysates of Gatifolia SD

with different hydrolysis time (20min, 60min, $120 \mathrm{~min}$ and $3.5 \mathrm{~h}$ )

Fig. 8 The linkage pattern of amino acid and sugar unit

Fig. 9 Snapshots of F80 (a) with a molecular weight of $100 \mathrm{kDa}$ and FS (b) with a molecular weight of $56 \mathrm{kDa}$

Fig. 10 Schematic of gum ghatti molecule adsorbed to oil droplet 

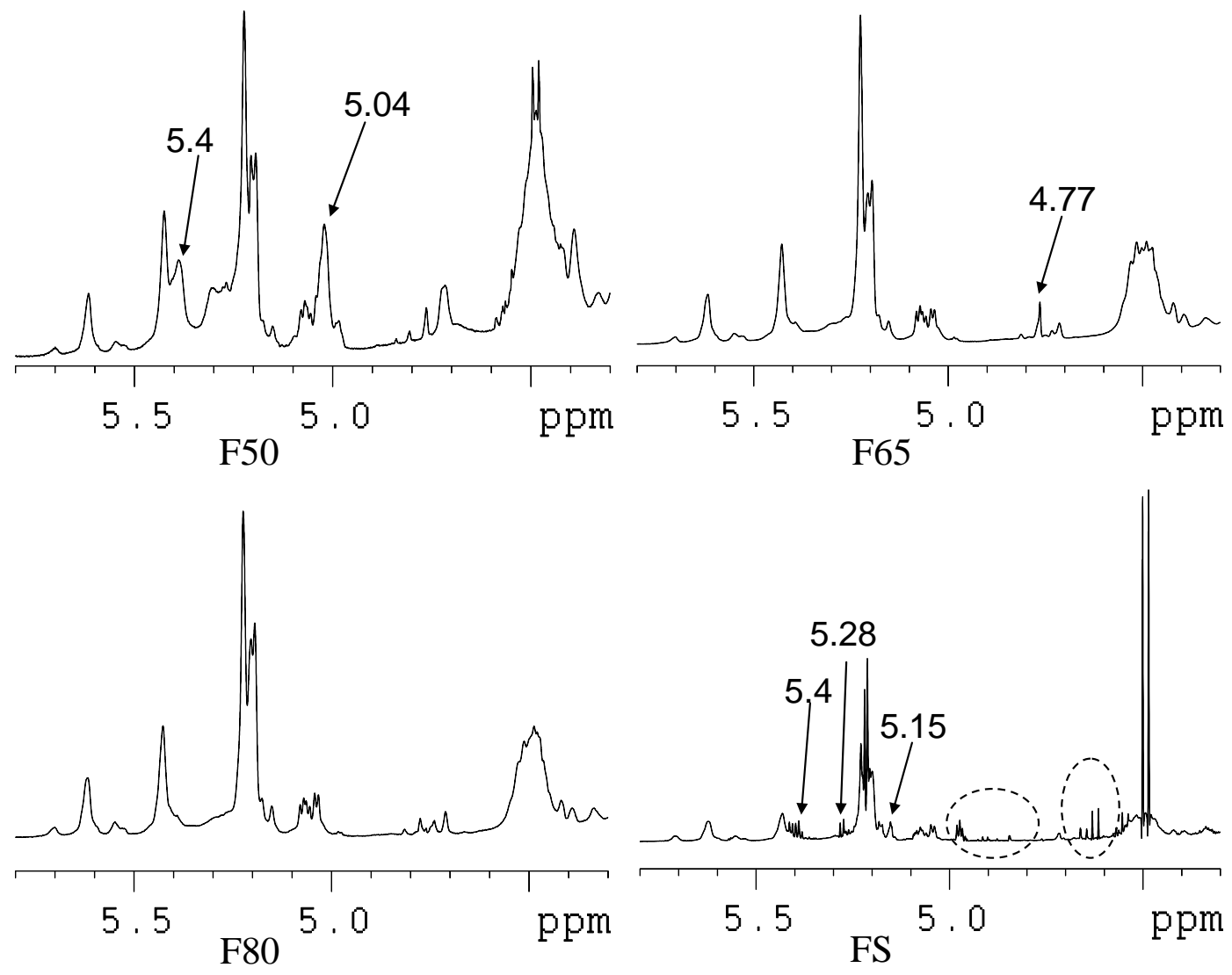

Fig. $1{ }^{1} \mathrm{H}$ NMR anomeric region of four fractions from Gatifolia SD 


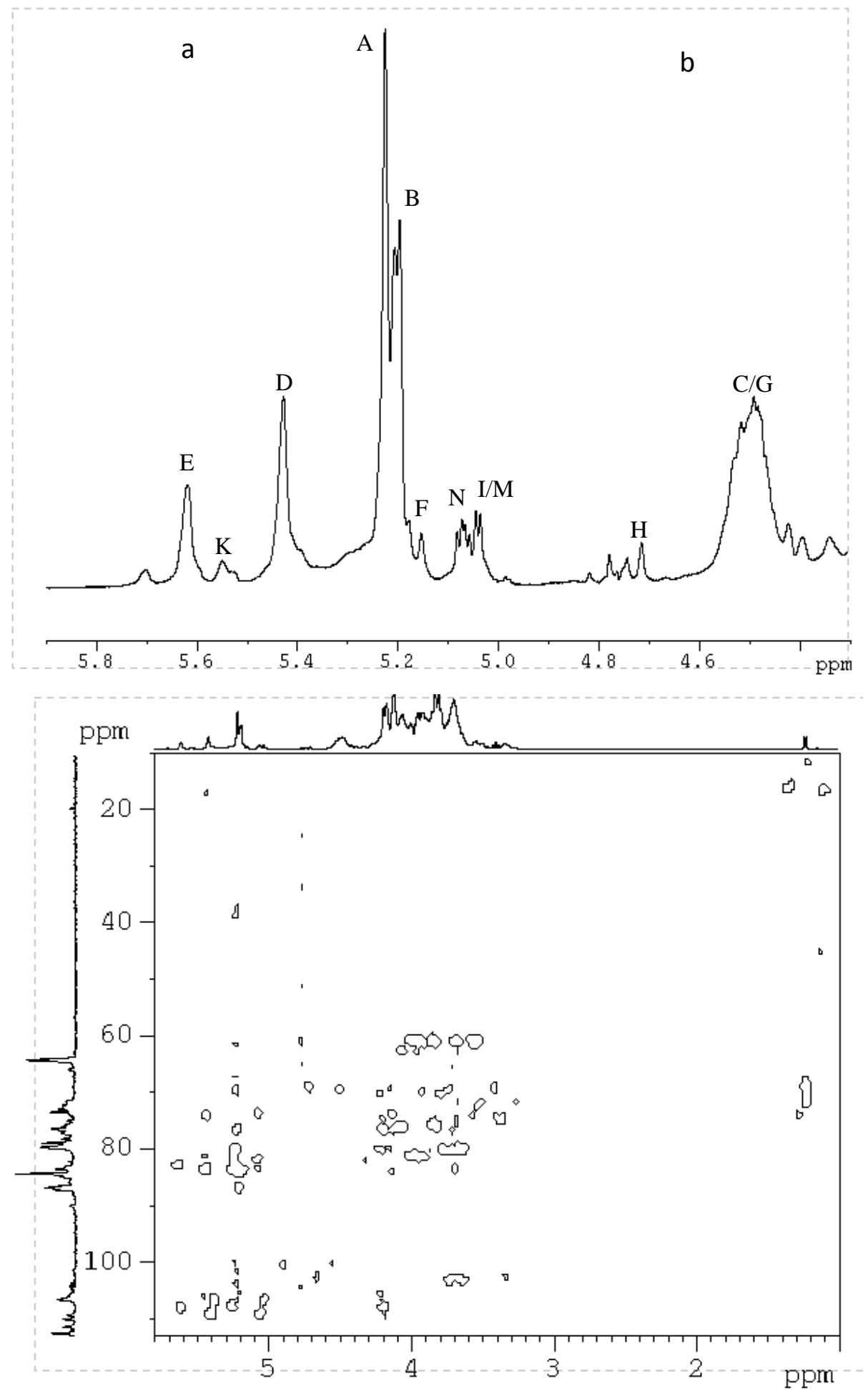

Fig. $2{ }^{1} \mathrm{H}$ NMR (a) and HMBC (b) spectrum of F80 isolated from gum ghatti. 


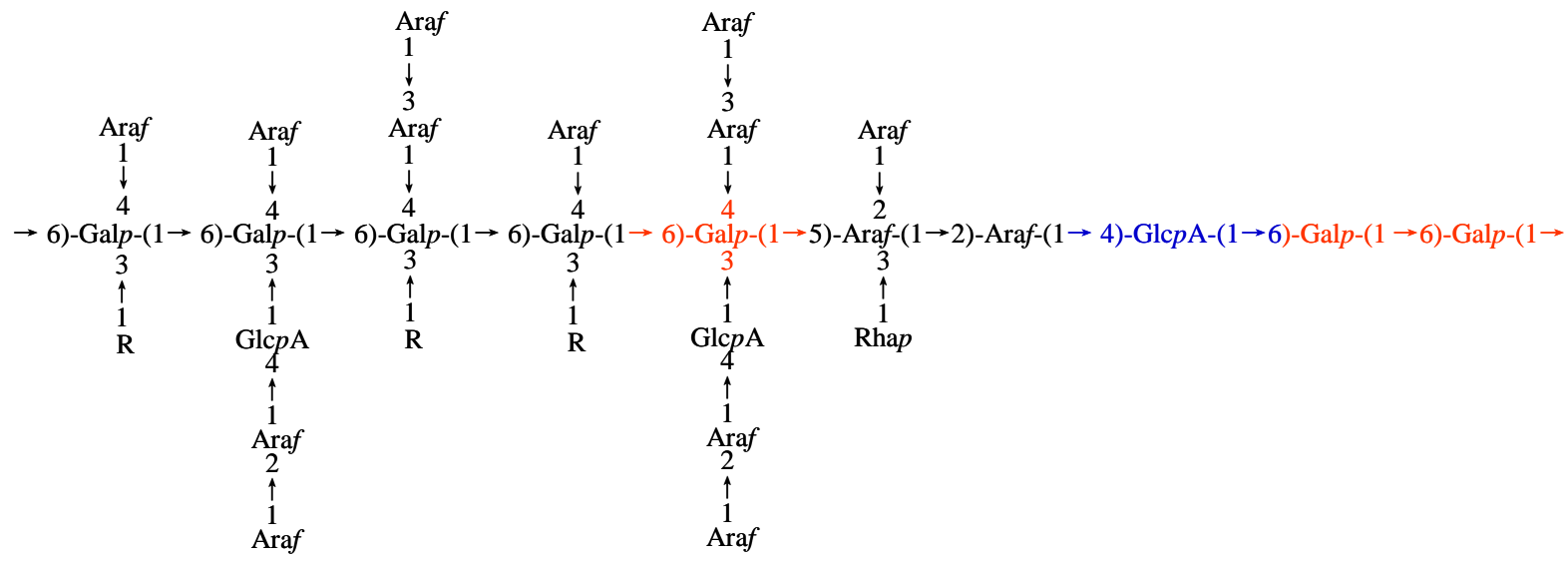

$R$ is one of the following groups: $\rightarrow 3)-\beta-D-G a l p-(1 \rightarrow, \rightarrow 5)-\beta-D-A r a f-(1 \rightarrow, \rightarrow 2,3-M a n p 1 \rightarrow$, $\mathrm{t}-\alpha-\mathrm{L}-$ Araf $1 \rightarrow$, t-GlcAp $1 \rightarrow$ and t-L-Arap $1 \rightarrow$.

Galactose has the $-\beta$-D configuration, while the arabinose and rhamnose are in the $\alpha-L$ form.

Fig. 3 Proposed structure of F80 

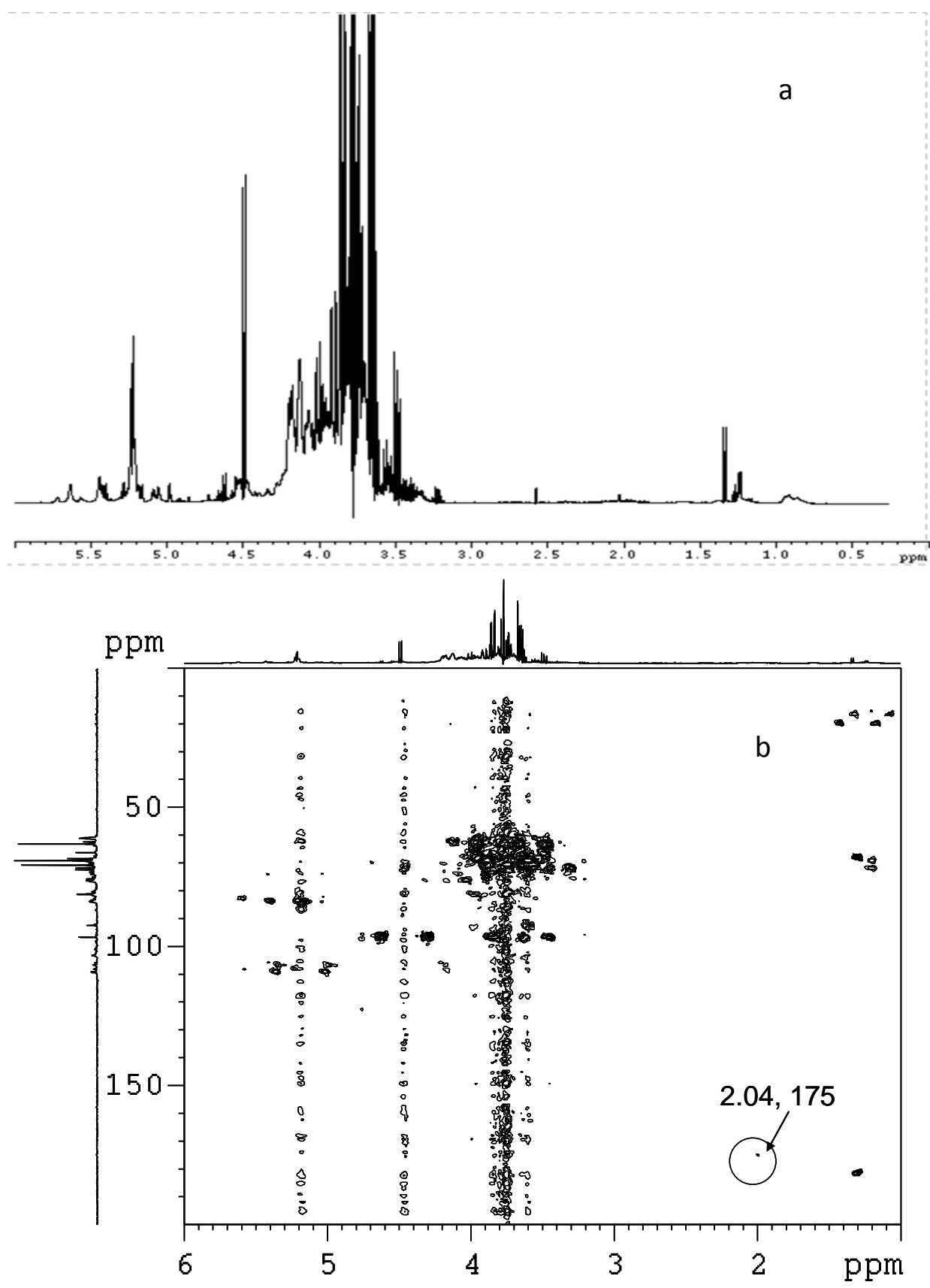

Fig. $4{ }^{1} \mathrm{H}$ NMR (a) and HMBC (b) of FS isolated from gum ghatti 


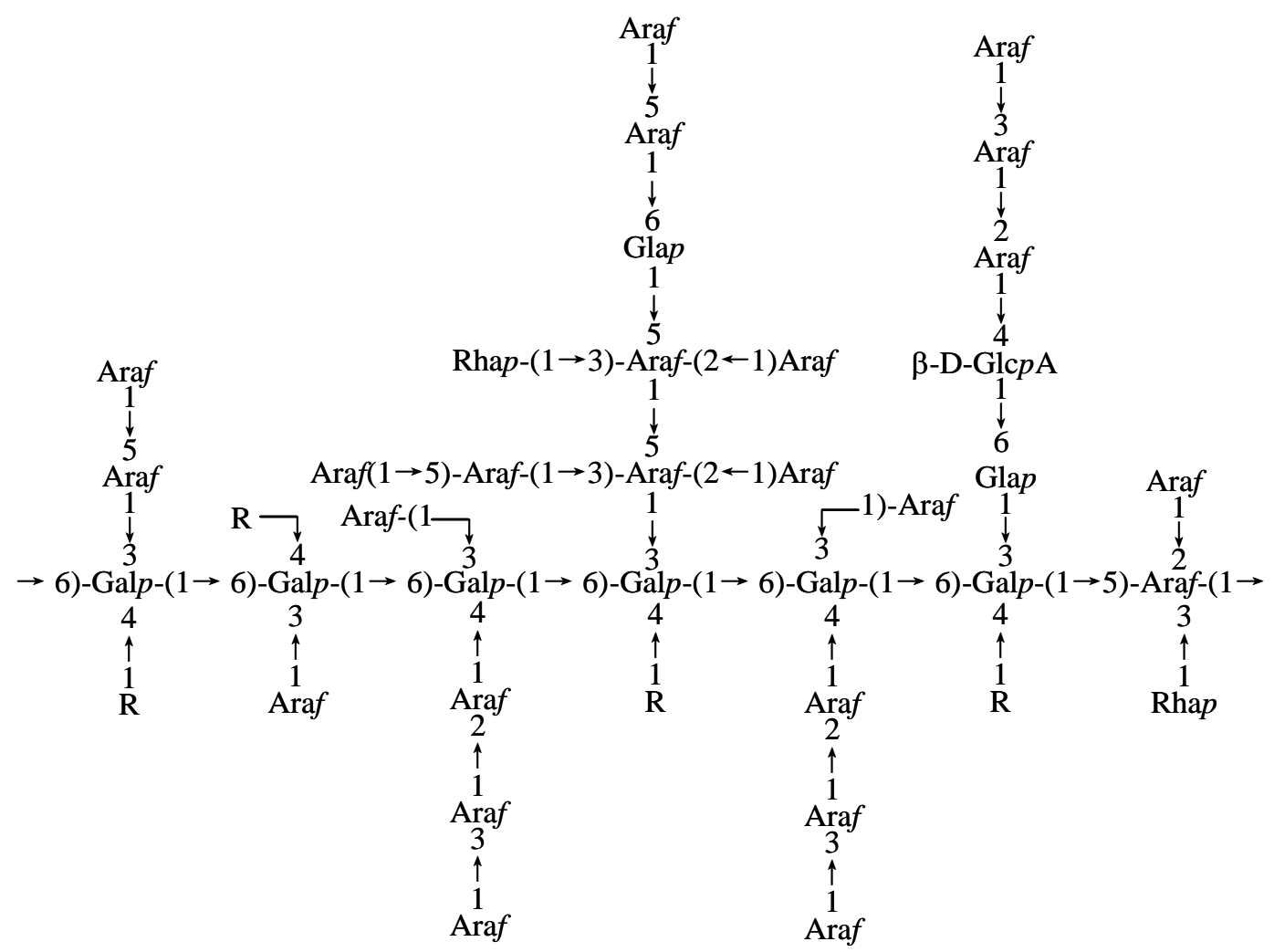

R can be represented by the following groups: $\rightarrow 2,3-$ Manp $1 \rightarrow, \rightarrow 3,4-$ Glc $p 1 \rightarrow, \rightarrow 4-$

Galp $1 \rightarrow$, T- $\alpha$-L-Araf $1 \rightarrow$, T-GlcpA1 $\rightarrow$, T-Galp1 $\rightarrow$ and T-L-Arap $1 \rightarrow$. Galactose has the $-\beta-D$ configuration, while the arabinose and rhamnose are in $\alpha-L$ form.

Fig. 5 Proposed structure of FS 


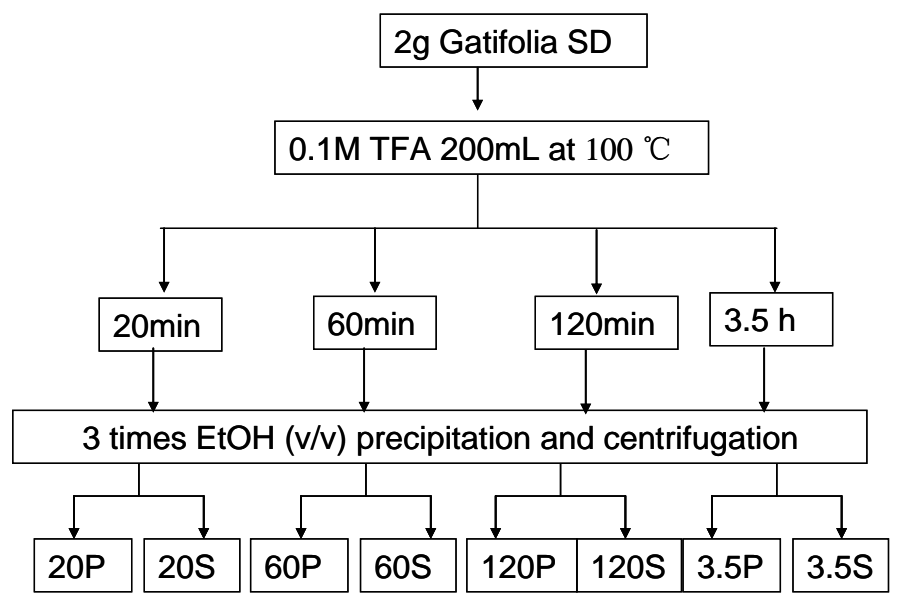

Fig. 6 Procedure for partial acid hydrolysis of Gatifolia SD 

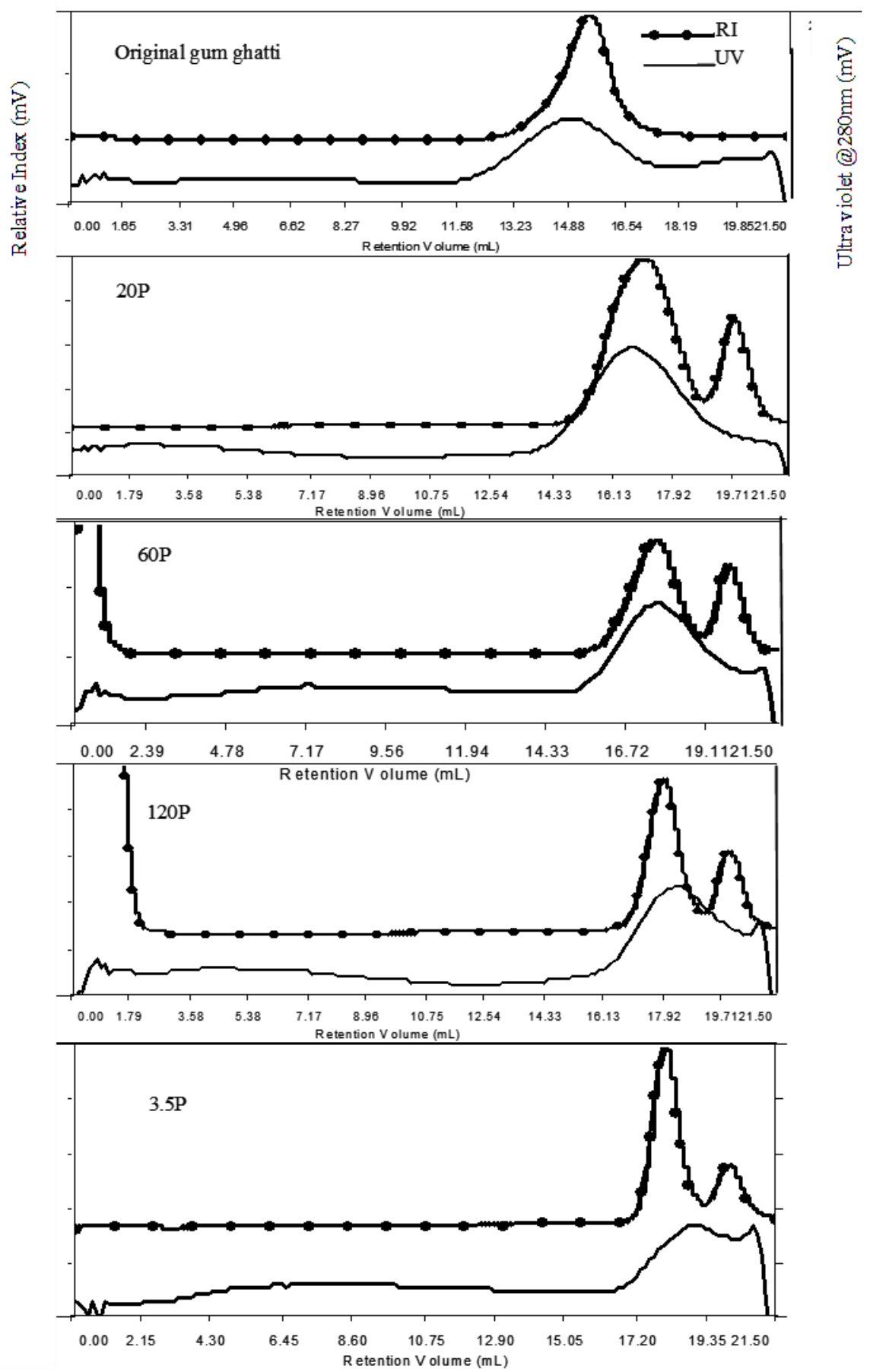

Fig. 7 HPSEC profiles from RI and UV signals of mild acid hydrolysates of Gatifolia SD with different hydrolysis time (20min, 60min, $120 \mathrm{~min}$ and $3.5 \mathrm{~h}$ ) 


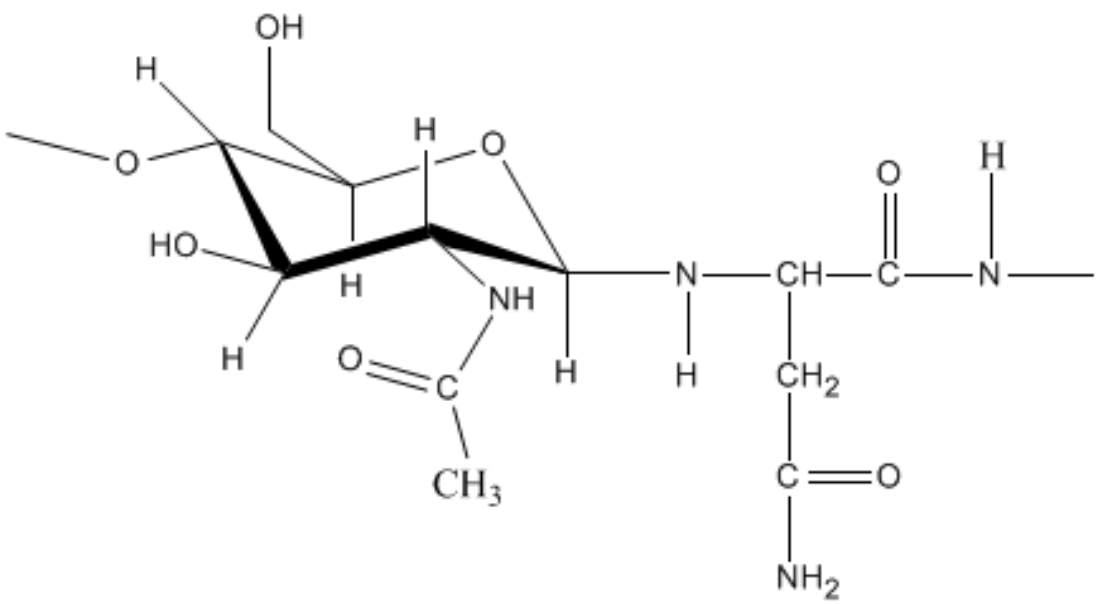

Fig. 8 The linkage pattern of amino acid and sugar unit 


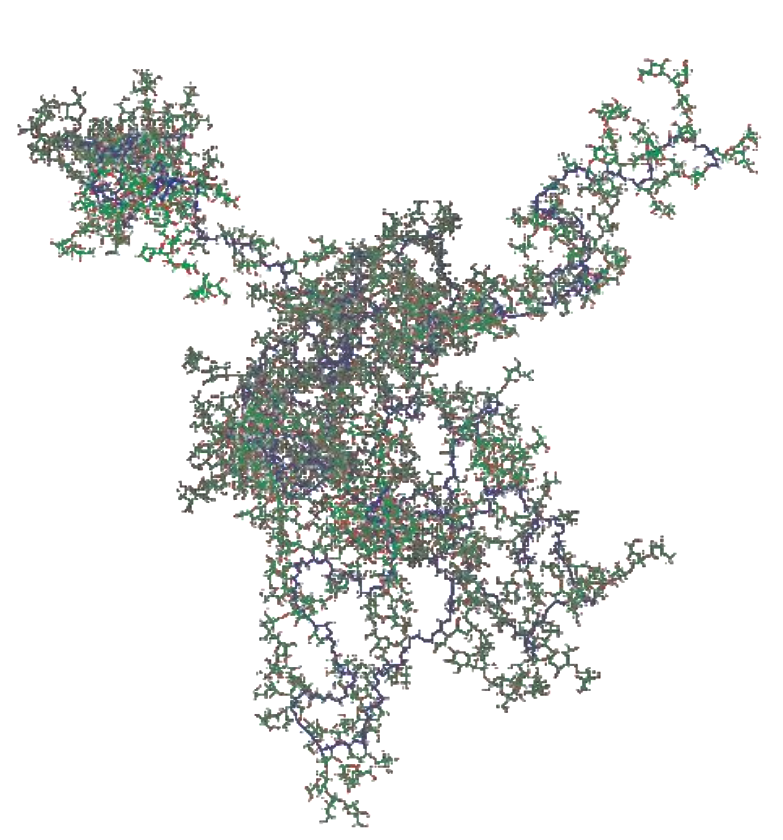

a

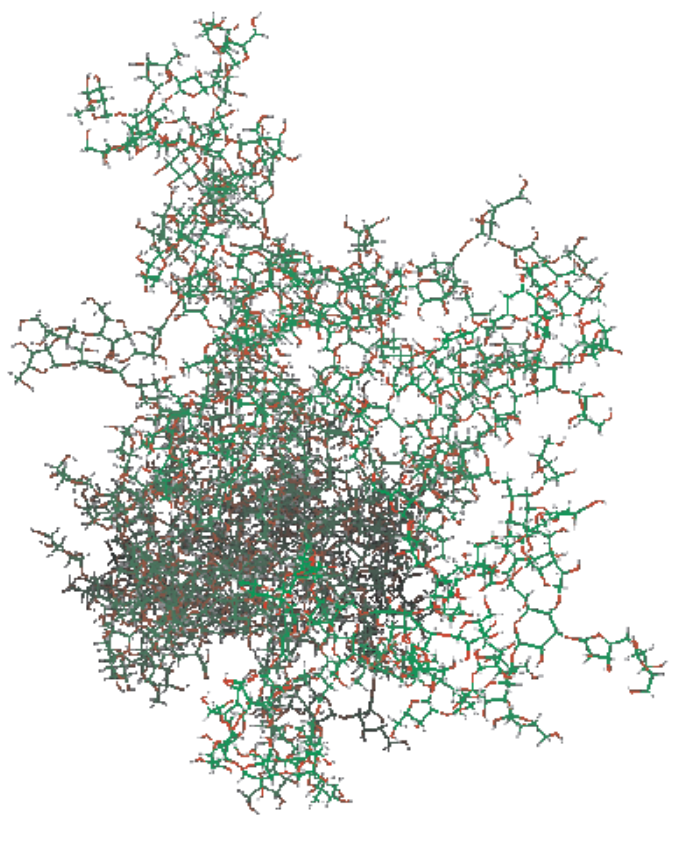

b

Fig. 9 Snapshots of F80 (a) with a molecular weight of $100 \mathrm{kDa}$ and FS (b) with a molecular weight of $56 \mathrm{kDa}$ 


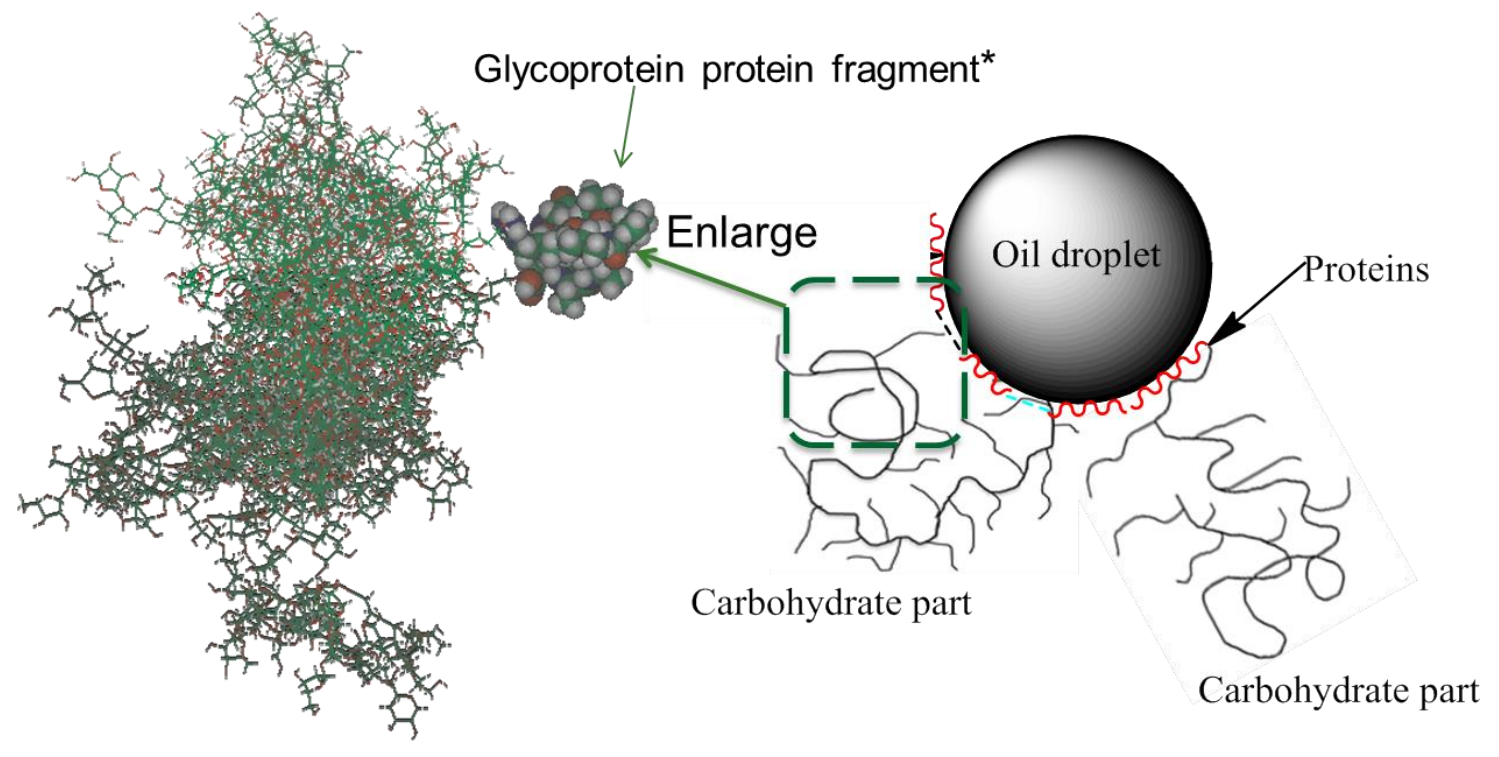

Glycoprotein carbohydrate moiety

Fig. 10 Schematic of gum ghatti molecule adsorbed to oil droplet 